\title{
O SAGRADO NO FEMININO: NARRATIVAS DE TERREIROS DO RECÔNCAVO BAIANO (SÃO GONÇALO DOS CAMPOS)
}

\author{
José Bento Rosa da Silva'
}

\section{Resumo}

Este artigo tem como objetivo revisitar, através das fontes orais, alguns terreiros de candomblé da cidade de São Gonçalo dos Campos, no Recôncavo da Bahia. É o desdobramento de uma pesquisa que investigou a trajetória de uma família de descendentes de africanos que, desde o século XIX, conseguiu manter, malgrado a escravidão, o sobrenome africano Cazumbá. Os relatos apontavam a presença de membros dessa família nos principais terreiros de Candomblé na cidade de São Gonçalo dos Campos e região, a partir da segunda metade do século XX. Destaque para o Terreiro da Lama, que existiu até meados dos anos sessenta do século passado.

Palavras chaves: Candomblé; Yalorixás; Religiosidade.

\begin{abstract}
This article aims to revisit, through oral sources, some candomblé "terreiros" (places of worship) from the region of São Gonçalo dos Campos city in the Recôncavo of Bahia. It is the unfolding of a research that investigated the trajectory of a family of African descendants that since 19th century managed to keep despite slavery the African surname: Cazumbá. The reports pointed the presence of this family members in the main candomblé "terreiros" in the São Gonçalo dos Campos city and region, from the second half of the 19th century. Highlight for the "Terreiro da Lama" that had its existence until the mid-sixties of the last century.
\end{abstract}

Keywords: Candomblé, yalorixás, religiousness.

\footnotetext{
${ }^{1}$ Possui doutorado em História pela Universidade Federal de Pernambuco (2001). Atualmente é professor associado da Universidade Federal de Pernambuco.
} 


\section{As Deusas, O Panteão e O Ocidente: À Guisa de Introdução}

No princípio, eram deusas e deuses, como apontam as diversas narrativas de origem (as denominadas mitologias), como, por exemplo: Aine e Badb, entre os celtas; Oxum e Oyá, entre os africanos; Anasya e Radha, entre os indianos; Gesta e Diana, entre os romanos, Freyga e Frigg, entre os nórdicos; e Atena e Afrodite, entre os gregos ${ }^{2}$.

Com o passar do tempo, nas sociedades ocidentais, as deusas foram excluídas do espaço sagrado, malgrado algumas exceções de setores mais "progressistas", tais como a do teólogo católico Leonardo Boff, que apontam para o feminino no sagrado ${ }^{3}$. Não resta dúvida que o medievo muito contribuiu para a expulsão do feminino do panteão, reduzindo-o ao masculino, até porque, na visão católica reinante, só havia lugar para um deus, rodeado de muitos dogmas.

Investigando a trajetória de uma família de descendentes de africanos no Recôncavo Baiano, os Cazumbá, deparei-me com narrativas acerca de terreiros existentes na região - narrativas tanto de homens quanto de mulheres -, nas quais sobressaíram a representação do feminino, sobretudo como yalorixás (mães de santo) e filhas de santo ${ }^{4}$. Reduzimos a "escala de minha observação" ${ }^{5}$, prestei mais atenção a essas narrativas e o resultado é o presente artigo, que brotou dos referidos relatos sem a pretensão de esgotar o assunto, uma vez que é um desdobramento de uma pesquisa mais ampla, que visou investigar a família acima mencionada, que em nossa opinião, distinguia-se dos demais descendentes de africanos pelas seguintes peculiaridades: a manutenção de um sobrenome bantu desde o século XIX e o fato de terem acumulado bens materiais da segunda metade do século XIX até meados do século XX. Hoje são vistos como os negros cujos antepassados foram detentores de propriedades na região de São Gonçalo dos Campos; portanto, têm uma "distinção social"'.

\footnotetext{
${ }^{2}$ Sobre as diversas mitologias do Ocidente e do Oriente, ver: SPALDING, Tassilo Oepheus. Dicionário das mitologias europeias e orientais. São Paulo: Ed. MEC./Cultrix, 1973. Sobre as mitologias africanas, ver: FORD, Clyd W. O Herói com rosto africano: mitos da África. São Paulo: Selo Negro, 1999.

${ }^{3}$ Estamos nos referindo à obra: BOFF, Leonardo. O Rosto Materno De Deus. 11. ed. Petrópolis: Vozes, 2012.

${ }^{4}$ Não podemos deixar de mencionar o clássico estudo de Ruth Landes sobre a presença da mulher no candomblé. LANDES, Ruth. A Cidade Das Mulheres. 2. ed. Rio de Janeiro: Ed. UFRJ, 2002. Sobre a estrutura e a tradição do candomblé no Brasil, ver: CAPONE, Stefania. A busca da África no candomblé. Rio de Janeiro: Pallas, 2004. Mais especificamente, sobre a formação do candomblé na Bahia, lócus deste artigo, ver: PARES, Luís Nicolau. A Formação do candomblé: História e ritual da nação jeje na Bahia. Campinas: Ed. Unicamp, 2006.

${ }^{5}$ Seguindo a perspectiva metodológica presente em: REVEL, Jacques (Org.). Jogos de Escalas: a experiência da microanálise. Rio de Janeiro: Ed. FGV, 1998.

6 "São Gonçalo dos Campos é um município brasileiro do estado da Bahia, localizado a $108 \mathrm{~km}$ da sua capital, Salvador. A cidade está situada na Região Metropolitana de Feira de Santana. Sua população
} 
Por outro lado, não podemos esquecer que esse sobrenome, ou nome de família, está relacionado com uma deusa africana, Zumbarandá, mais conhecida como Zumba. Segundo o antropólogo angolano Fernando Wilson Sabonete, o processo etimológico do sobrenome Cazumbá pode ser assim resumido:

[...] Kazumbá, Kazumba ou ainda Zumba; existem nomes em Angola, no sul temos muitas pessoas com esse nome [...] a sua pergunta seria se é nome próprio ou sobrenome? [...] Em primeiro lugar, os nomes e sobrenomes se confundem muito em Angola, eu tenho certeza que Zumba pode ser nome próprio ou sobrenome de alguém, o que difere em Angola por vezes [é o] grau, por exemplos: em todas línguas bantas, a palavra que leva o prefixo [ka] Kazumba igual o grau diminutivo. O pai, no caso, tem o nome de Zumba grau superlativo, e essa é primeira confusão, e a segunda é de não termos regra de nomes e sobrenomes em Angola. E agora a letra [k] foi substituída por portugueses [c] e naturalmente foi evoluída para acento. Normalmente esse nome é comum na etnia Chokwe, Ganguela e Nhemba, e os chokwes são famosos nos rituais e máscaras. Zumba também está relacionado à divindade $[\ldots]^{7}$.

Arthur Ramos, ao investigar a contribuição dos africanos de língua bantu no Brasil, evidenciou o contexto "genealógico" da palavra Cazumbá, nele Zumba não se encontra. Ao que nos parece, na diáspora ela já havia sido “expulsa” do panteão:

[...] Outro espírito ou divindade é o Nzambi, Zumbi ou Cazumbi, que não deve ser confundido com o grande Deus Zambi. No Congo e em Angola, o Zumbi ou Cazumbi é um nome genérico para os espíritos malfazejos que tiram o juízo aqueles de quem se apessoam. Outras vezes, são deuses lares ou espíritos caseiros que rodeiam as pessoas, intervindo até nos atos domésticos $[\ldots]^{8}$

No entanto, na narrativa original, ela estava bem presente, ajudando na construção do universo, inclusive criando os seres humanos a partir da lama. Coincidência ou não, um dos terreiros onde os Cazumbás participavam era denominado de Terreiro da Lama, em São Gonçalo dos Campos, como veremos adiante. Pois bem, vejamos a participação de Zumba ${ }^{9}$ na obra da criação:

estimada em 2019 era de 37.550 habitantes. O município, foi criado a partir dos territórios das freguesias de São Gonçalo dos Campos da Cachoeira e de Nossa Senhora do Resgate das Umburanas, que foram desmembrados de Cachoeira por Lei Provincial de 28.07.1884, chamando-se então São Gonçalo dos Campos. Em 1931, teve o nome simplificado para São Gonçalo, mas, em 1943, retomou a denominação atual. Antigamente os enfermos de tuberculose iam até a São Gonçalo, pois seu clima era considerado propício ao tratamento. Existem arquivos e pessoas que comprovam que D. Pedro II passou por são Gonçalo para se curar de tuberculose. A sede, criada freguesia com a denominação de São Gonçalo dos Campos da Cachoeira, foi elevada em 1689 à categoria de cidade por Lei Estadual de 25.06.1895." (Disponível em: https://pt.wikipedia.org/wiki/S\%C3\%A3o_Gon\%C3\%A7alo_dos_Campos. Acesso em: 11 abr. 2020).

${ }^{7}$ Informações cedidas por Fernando Wilson Sabonete em 21 de fevereiro de 2011 por $e$-mail.

${ }^{8}$ RAMOS, Arthur. Introdução à antropologia brasileira. Rio de Janeiro: Ed. da Casa do Estudante, 1943, v. 1 (As culturas não europeias), (Coleção Estudos Brasileiros da CEB), p. 452-453, grifos nossos.

${ }^{9}$ Zumba, síncope de Zumbarandá. 
A Senhora Zumbarandá, que passava os dias preparando o barro da criação, apanhando água, misturando-a à terra, formando os corpos e as formas de tudo que era criado, começou a Se achar muito assoberbada com as diversas encomendas recebidas. Na primeira oportunidade que conseguiu, foi falar com o Senhor Nzambi e pediu ajuda. O grande Maestro do Universo apanhou um pouco de Sua Energia, entregou à Senhora e disse: "Aqui está a ajuda que você necessita, crie e instrua para lhe ajudar."

Zumbarandá voltou ao Seu pântano, criou um boneco com o Seu barro misturando na massa o punhado de Energia Divina, criou um homem jovem, bonito, forte, criativo e inteligente. Como era muito bonito, deu-lhe o nome de Hongorô, o arco-íris. Hongorô passou então a Se encarregar de apanhar a água para que a Grande Senhora fizesse seu barro e começou a moldar as formas da criação e, por ser muito criativo e de bom gosto, começou a colorir cada criação com cores específicas.

Quanto mais os Mikisi queriam criar ervas, flores, animais, minerais, etc., mais serviço aparecia para Zumbarandá e Hongorô. Muito inteligente, Hongorô pegou um pouco de Seu próprio ser, pegou um bocado do barro da Grande Mãe e criou uma mulher lindíssima, jovem, forte, criativa e inteligente. Zumbarandá Se encantou com a criação de Hongorô e perguntou: "O que fará para nos ajudar essa maravilhosa criatura?". Hongorô, neste momento exato, deu à Sua criação o dom de "serpentear" pela terra e, assim, conseguindo fazer com que a tão necessária água chegasse rapidamente ao pântano de Sua Senhora. Zumbarandá então disse: "Já que é parte de Seu ser e lidará com a água, daremos a Ela o nome de Hongoromenha".

O tempo passou e Hongoromenha começou a reclamar que os homens e os animais, durante o percurso, sujavam a água que Ela conduzia e, por mais que pedisse, eles não A atendiam. Zumbarandá deu a Ela o poder de se transformar em serpentes, de todos os tamanhos para assustar a todos, afastando-os das águas. Katendê, ao saber do problema, pegou várias de suas ervas, misturandoas, formou um líquido venenoso e deu a Hongoromenha: "Isso é para Sua defesa, o efeito desse líquido causará imensas dores e até a morte de quem quiser Lhe afrontar".

O tempo continuou passando e tudo corria bem, a criação estava plena de formas e cores, Lembá estava satisfeito com a imensa diversidade de seres nos quais Ele soprava o dom da vida. Até que Nzazi, com sua voz de trovão, pediu a Zumbarandá que a água ficasse disponível, também para os seres que habitavam o planeta, não era justo que eles não tivessem acesso a tal regalia. Dandalunda, com seu coração de puro amor, formou então por todo o mundo rios que conduziriam a água em todas as direções tornando-a fácil a toda a criação. Hongorô então teve uma idéia maravilhosa e pediu à Grande Senhora que conseguisse que uma parte da água fosse ao Duilo e tornasse a cair sobre a terra, reenchendo os reservatórios e caindo em todas as partes do mundo. Zumbarandá deu então a Hongorô o dom de formar um canal de ligação entre o céu e a terra conduzindo a água que voltaria à terra em forma de chuva e Ele, então, criou o arco-íris presente até hoje em todos os lugares onde há água iluminada pela luz do Sol. ${ }^{10}$

As narrativas colhidas na cidade de São Gonçalo dos Campos, no estado da Bahia (onde há a centenária Irmandade de Nossa Senhora da Boa Morte), no ano de 2015, às vésperas de mais uma edição da Festa da referida divindade, são as nossas fontes privilegiadas na ressignificação das representações das senhoras, que no passado eram

\footnotetext{
${ }^{10}$ DOBURU. A Nação Angola: Lenda de Nzaze, Uma lenda sobre Zumba, Ngunzu, Nkisi Nkosi, dandalunda, Pambu. $\quad$ s.d. $\quad$ Disponível em: http://daburu.ucoz.com.br/index/a_nacao_angola_lenda_de nzaze uma_lenda_sobrezumba_ngunzu_nkis i_nkosi_ndandalunda_pambu njila/0-43. Acesso em: 12 ago. 2019.
} 
Yalorixás, mediadoras entre o sagrado e as deusas ancestrais; que também tramitavam entre as religiões afro-brasileiras e o catolicismo popular. "Tonho de Abécio" é o nosso guardião das memórias do sagrado no feminino.

\section{O Terreiro da Lama: História, Memórias e Narrativas}

O Terreiro da Lama foi um dos mais conceituados na cidade de São Gonçalo dos Campos e região. Ouvimos muitas narrativas acerca da sua fundação, trajetória, das Yalorixás, das festas e a descrição de alguns dos rituais. Finalmente encontramos alguém que nos levou aonde foi fundado o Terreiro e aonde ele terminou: Antonio Raimundo Nunes Costa, conhecido como Tonho de Abécio. Aliás, foi ele quem nos contou o que ouvira de muitas Yalorixás, inclusive de Mãe Silu, uma grande liderança do Terreiro da Lama, falecida nos anos 70 do século passado.

Nossa primeira referência sobre o terreiro veio-nos através do Babalorixá Godofredo Copque Daltro, Godô, de um Terreiro da cidade de Franco da Rocha, estado de São Paulo. Ele, juntamente com sua mãe, a Yalorixá Honorina Copque Daltro, no passado participou do Terreiro da Lama, quando moravam na Bahia; portanto, o "Ilê" de Franco da Rocha tem vínculos históricos com o Terreiro da Lama.

Já dissemos que as Yalorixás de São Gonçalo, inclusive as do Candomblé da Lama, tinham estrita ligação com a Irmandade de Nossa Senhora da Boa Morte. Luciana Falcão Lessa, que pesquisou a Irmandade da Boa Morte no período compreendido entre 1900 e 1950, evidenciou essa ligação umbilical entre irmandade católica e religiosidade afro-brasileira. E mais, transcreveu de um jornal local, "a batida policial" no Candomblé da Lama, nos idos anos 40, em pleno Estado Novo. Segundo o jornal, o delegado não viu anormalidade alguma no terreiro, muito pelo contrário, fora muito bem recebido pelo Mestre Lázaro:

[...] enquanto meus companheiros caíram na devoção, eu dando um pouco de repouso a este corpo um tanto já gasto e pesado, aceitei uma cômoda preguiçosa, onde de início até um cochilo tirei. De tudo quanto ali observei, nada mais vi senão uma aglomeração alegre e inofensiva cada um fiel aos seus princípios e obedientes à crença dos seus antepassados [...]. Quem for à Lama verá que tudo ali não passa de distração dentro da ordem e do respeito, nem mesmo quando fiéis mais exaltados, ao rufar de cuícas tamborilantes, depositam flores às braçadas aos pés dos seus santos e preparam alegres e risonhos presentes que, às duas horas, uma comissão de três leva à cachoeira e, oferece à ilusória e divertida mãe d'água de tanta História bonita para ninar menino $[\ldots]^{11}$

\footnotetext{
${ }^{11}$ JORNAL A RAZÃO. 02.08.1944 In: LESSA, Luciana Falcão. Senhoras do Cajado: um estudo sobre a Irmandade da Nossa Senhora da Boa Morte de São Gonçalo dos Campos - Bahia (1900-1950). Dissertação (Mestrado em História) - Universidade Federal da Bahia (UFBA), Salvador, 2005, p. 96.
} 
A mesma opinião não tinha o vigário da paróquia Bráulio Seixas, que, num domingo após a missa, denunciou a conivência do delegado Gumercindo Dias com as práticas do candomblé na cidade de São Gonçalo dos Campos. O repórter do jornal ou algum informante registrou o desabafo, que foi publicado nas páginas do Jornal Razão, com o seguinte título: "Candomblé sim, mas serenata não". O jornal falava que o mesmo delegado que não permitia que "um grupo de rapazes qualificados como bons moços da sociedade" fizessem serenata, por outro lado, permitia os candomblés noite adentro. Foi nesse contexto que mencionou o desabafo do vigário:

[...] Após a missa conventual de domingo o Revmo. Cônego Bráulio Seixas, justamente revoltado clamou contra o fato, positivamente denunciador do abandono a que chegou nossa terra, de estar a cidade dominada e absorvida pelas casas de candomblé.

Claro que [o] responsável por este absurdo o Sr. Gumercindo Dias, delegado de polícia, único sobre quem recai a culpa, senão o crime de haver transformado São Gonçalo n'um terreno de mães d'água e pais de santo[... $]^{12}$

A Lama era um terreiro conceituado. Tanto na dissertação de mestrado em História de Lessa, já citada, quanto na dissertação de mestrado, também em História, de Luiz Cláudio Dias do Nascimento, encontramos depoimentos que corroboram o que ouvimos quando de nossa estadia em São Gonçalo dos Campos, inclusive visitando as localidades onde o terreiro existiu e conversando com contemporâneos de Yalorixás da época de mãe Silu ${ }^{13}$.

Nosso guia em São Gonçalo dos Campos, na segunda viagem a campo, em julho de 2015, foi Tonho de Abécio. Mas ele não foi apenas um guia. Ele foi, sobretudo, um narrador. Narrador conforme a categoria preconizada por Walter Benjamin ${ }^{14}$. Literalmente nos levou pela mão, apresentando a cidade, rememorando os lugares, personagens, falando, gesticulando, alternando a voz, entre tons graves e agudos, entremeados de silêncios que tanto representavam ausências, quanto presenças, pois, segundo um provérbio africano: "só se morre quando se é esquecido".

Lugares de memórias ${ }^{15}$ : o corredor que nos levou ao antigo território da Lama, a árvore tombada em virtude do temporal que se abateu sobre a região (era uma árvore do

\footnotetext{
12 JORNAL A RAZÃO. 09.01.1948.

13 NASCIMENTO, Luiz Cláudio Dias do. Terra De Macumbeiro: redes de sociabilidades africanas na formação do candomblé jêje-nagô em Cachoeira e São Félix-Bahia. Dissertação (Mestrado em Antropologia) - UFBA, Salvador, 2007.

${ }^{14}$ BENJAMIN, Walter. Obras Escolhidas: magia e técnica, arte e política. São Paulo: Brasiliense, 1993.

${ }^{15} \mathrm{Na}$ concepção de Pierre Nora é uma denominação para locais que remetem a acontecimentos do passado. Sobre esta questão, ver: NORA, P. Entre Memória e História: A Problemática dos lugares. Projeto História, Revista do Programa de Estudos Pós-Graduados em História e do Departamento de História da PUC-SP, São Paulo, n. 10, 1993.
} 
Orixá Obaluaiê), a antiga fonte de Nanã, que se metamorfoseara num lago para matar a sede do gado que ocupa o que antes era a Fazenda da Lama com seus arbustos nativos, hoje reduzidos a pastagem. Ao passarmos pela localidade, Tonho de Abécio explicounos: "Aqui era a fonte do arrozinho. A fonte encantada. Onde os Iaôs tomavam o banho às quatro horas da madrugada, antes do sol nascer. Era desta fonte também que se fazia o osé do santo; pegar água para encher as quartinhas do santo, para fazer as obrigações. Aqui era mata fechada".

Foi nessa caminhada, embalada pelas narrativas de Tonho de Abécio, que apreendemos muitos relatos sobre essas senhoras, mediadoras entre os Orixás e os seus descendentes, mesmo para os que não creem neles. E mais: nas narrativas a presença dos Orixás femininos e masculinos, lembrando que "Deus é menino e menina, masculino e feminino".

Tonho, dentre outras coisas, disse ter ouvido que, no passado, na época em que o candomblé era perseguido pelas autoridades policiais, em uma diligência ao terreiro para obstar os ritos sagrados, um delegado teria ameaçado as sacerdotisas e sacerdotes dizendo que só não os prenderia porque eram velhos. Os religiosos resignadamente nada responderam, pelo contrário, calaram-se diante da autoridade. Ao saírem, a sacerdotisa teria afirmado que eles não passariam da porteira para fora. Passados algumas horas, delegado e policiais retornaram ao barracão, pois que não conseguiram passar além da porteira devido a uma grande lama que impossibilitou que o jipe seguisse viagem. Então a sacerdotisa ou sacerdote serviram a eles uma boa refeição. Por ali mesmo, eles dormiram e seguiram somente ao amanhecer do dia.

Diz Tonho que foi mãe Judite quem lhe contou esse fato, tanto quanto mãe Silu, da qual ele cuidara no leito de morte. Disse mais, que esses acontecimentos remontam tempos passados, à época de pai João, um africano fundador do terreiro da Lama. Outras narrativas atribuem a mãe Silu tal acontecimento, outros a mãe Judite; mas uma coisa é certa, a narrativa é corrente na voz dos que contam sobre o terreiro da Lama.

Essa narrativa pode ter sido reforçada após o depoimento do delegado no jornal acima citado, na década de 40. Ele inclusive disse que "tirou um cochilo" quando fora fazer uma notificação no terreiro da Lama. Fato que ao certo desgostou o reverendíssimo padre Bráulio, que também se queixara publicamente dos desmandos das autoridades com a prática do candomblé na cidade de São Gonçalo dos Campos.

Abécio nos contou a origem do terreiro da Lama, segundo a narrativa de mãe Silú e de outras Yalorixás que ele conhecera quando jovem, aliás, ele próprio "lavou a cabeça" 
no terreiro da Lama, mas nessa ocasião, na década de 60, o terreiro já havia mudado de localidade, não estava mais no local onde fora fundado, mas na atual Avenida Cazumbá. Estivemos lá, ele nos mostrou a casa, hoje fechada, mas ele acredita que os objetos sagrados ainda possam estar lá:

[...] Olha, o candomblé da Lama quando eu alcancei, não tinha mais aquela tradição toda. Já tinha morrido muitas mulheres. Eu conheci a Tia Antônia Cazumbá, eu a conheci com uma conta azul no pescoço. Uma conta de Ogum. Agora não sei assim da participação dela no candomblé da Lama.

Lembro de Tia Lalu, antiga daquela época. Porque o candomblé [...] começou com pai João. Ele fez um barco com dois filhos ${ }^{16}$ : Tia Judite e Titio Joaquim. Forma os primeiros filhos de santo dele da Lama. Ele fez estes dois. Tia Judite de Aganju e Tio Joaquim de Ogum. Então, quando ele morreu, ele deixou estes dois para cuidar da casa, os seus sucessores.

Dizem que Tia Judite era uma mulher assim muito reservada, cuidadosa das coisas dela, multo oculta. Tio Joaquim era assim muito afoito. Toda pessoa de Ogum é muito afoita mesmo [acrescenta].

[...] A Lama era lá na Nova Brasília, na antiga estrada de ferro. Temos a casa onde terminou o terreiro, aqui na cidade mesmo, na Avenida Cazumbá. Foi transladado o terreiro para aqui, venderam a roça. Quando venderam a roça, foi um problema sério, muita coisa aconteceu. Foi mais ou menos em $1961[\ldots] .^{17}$

Foto 1: Casa onde terminou o candomblé da Lama

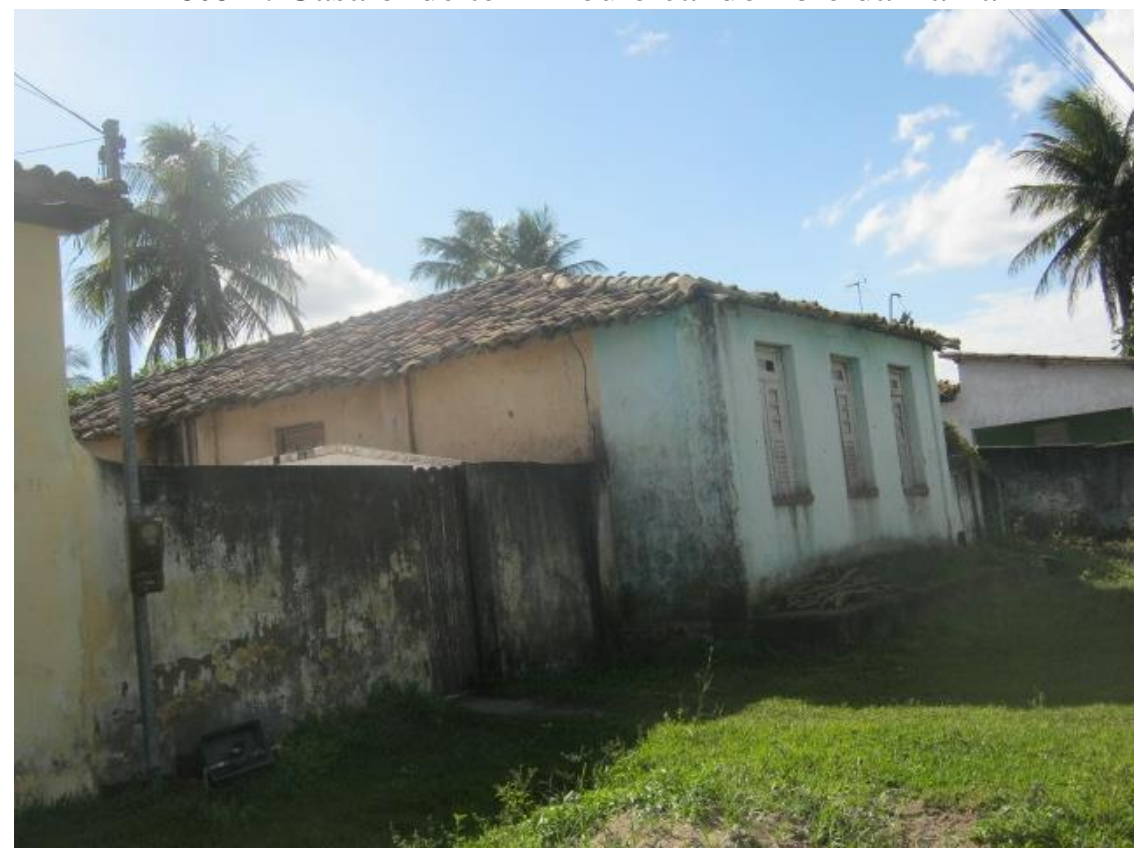

Fonte: Acervo do autor.

\footnotetext{
${ }^{16}$ Denominação ao rito de iniciação, também conhecido como "feitura do santo".

17 Entrevista com Antônio Raimundo Nunes Costa, "Tonho de Abécio”, 71 anos. Em São Gonçalo dos Campos (BA), em 22 de julho de 2015.
} 
Foto 2: Tonho de Abécio observando a casa onde terminou o candomblé da Lama nos $\operatorname{anos} 70$

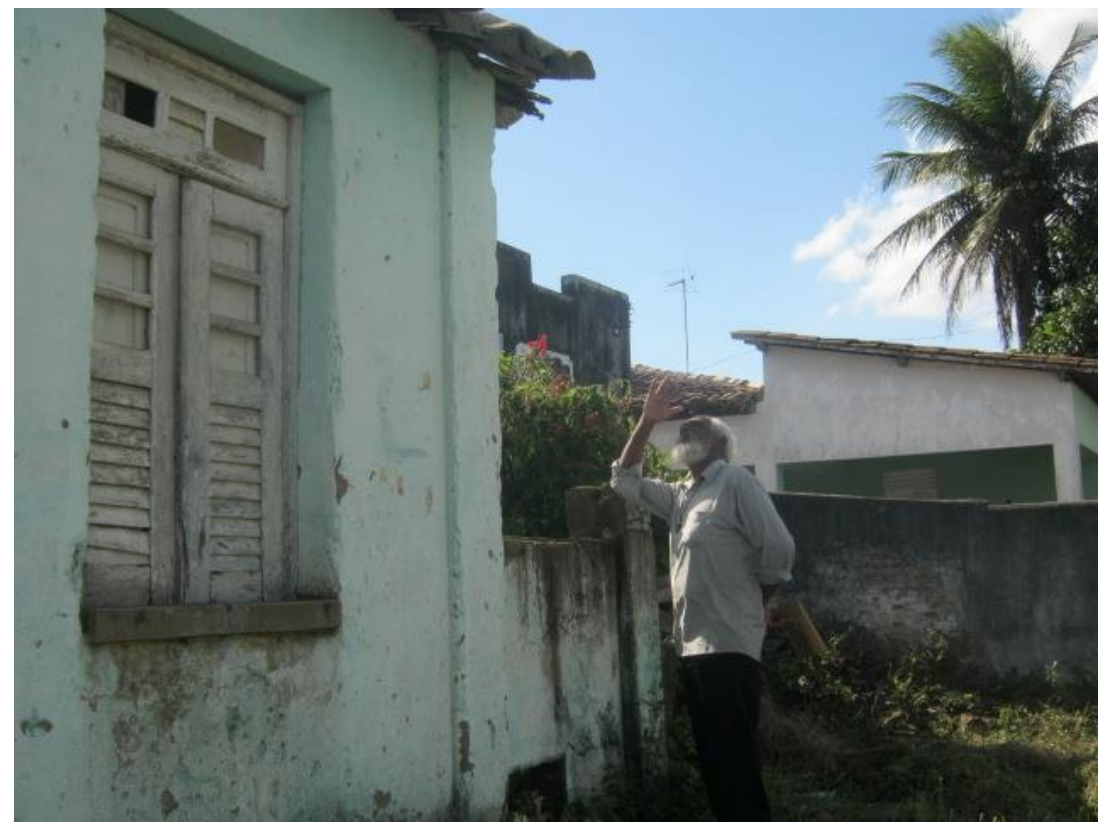

Fonte: Acervo do autor.

Nossa fonte de informações nos mostrou onde era a fonte encantada de Nanã, na localidade denominada Arrozinho. Hoje a antiga fonte foi transformada numa lagoa. Foi nesse momento que ele fez a seguinte descrição: “[...] A fonte encantada era onde as Yaôs tomavam banho antes do sol nascer, às quatro horas da manhã. O Osé do santo era feito desta fonte, ou seja, de onde se pegava água para levar para as quartinhas dos santos, para fazer as obrigações do santo[...]"18

Ao longo do caminho, encontramos uma árvore que havia caído em virtude de um grande temporal que se abateu sobre a região. Ele então nos explicou a função de tal árvore no candomblé da Lama: "Esta árvore chama-se sete cassaca. Era a árvore onde se colocava as obrigações de Obaluaiê. Penduravam-se as oferendas para ficar no tempo. Não se deixava no chão, porque os bichos do mato podiam vir comer. Os galos, as oferendas, as coisas sérias do Velho Obaluaiê eram na árvore, não era no chão[.... $]^{19,}$

A cada informação que nos dava, Tonho de Abécio fazia questão de dizer que seu amigo, Antônio Borges Falcão, teria muito mais informações que ele, uma vez que era mais velho e que fora quem o levara para o candomblé da Lama. Infelizmente não pudemos entrevistar Antônio Borges por se encontrar em tratamento de saúde fora da

\footnotetext{
${ }^{18}$ Entrevista com Tonho de Abécio.

${ }^{19}$ Entrevista com Tonho de Abécio.
} 
cidade. Mas encontramos a narrativa de um contemporâneo de Antônio Borges, Geraldo Alves Pereira, que concedeu uma entrevista a Luciana Falcão Lessa, já mencionada $\operatorname{acima}^{20}$. Disse-nos ele:

[...] Tia Silu não chegou a morrer muito velha não. Não chegou a oitenta anos de idade! Ela morreu em nove de fevereiro de mil novecentos e setenta e dois. Quem cuidou dela foi eu. Eu e o sacristão aqui da igreja, o Antônio. Ele nasceu e se criou lá [na Lama]. Ele deve ser uns treze anos mais velho que eu. Ele tem muito conhecimento sobre o candomblé da Lama. Ele conviveu lá mesmo! Quem me levou pra lá foi ele, isso no ano de mil novecentos e sessenta e oito. Eu estava meio adoentado. Só fui lá lavar a cabeça. Não participei de nada. Eu fui receber o Amassi e nunca mais tirei[... $]^{21}$

Geraldo Pereira, que na época da entrevista acima mencionada tinha 93 anos, era um memorialista da cidade de São Gonçalo dos Campos. O professor Edivaldo Daltro, ex-diretor de escola e ex-secretário de educação, que também nos narrou sobre o terreiro da Lama, disse-nos que o senhor Geraldo era um verdadeiro arquivo vivo sobre a cidade. Infelizmente não o conhecemos. O depoimento dele acerca do terreiro da Lama é revelador:

[...] As irmãs [da Boa Morte] tomavam parte na Festa de São Gonçalo, incorporadas e bem trajadas, frequentavam o candomblé da Lama, que pertenceu a Joaquim de Brito, vinha até gente de Cachoeira para as festas tinha samba, samba de roda, levavam uma semana tocando atabaques. $\mathrm{O}$ candomblé era comum em São Gonçalo, e esse candomblé era o maior porte. Ah! Tinha a Tia Sancha, vinha gente do sertão todo, fazia caruru, era uma semana de festa, chegava cargas de galinhas $[\ldots]^{22}$

\section{Revisitando O Terreiro de Tia Sancha}

Nas narrativas de Abécio sobre os terreiros de candomblé de São Gonçalo e região, Tia Sancha tem "cadeira cativa". Ele a conheceu e frequentou seu terreiro, juntamente com Maria Alice, sobrinha de Sancha, à qual tivemos o prazer de ser apresentados por Tonho de Abécio, quando de nossas andanças por São Gonçalo. Foi ele quem nos levou até o local do terreiro, que se encontra fechado desde a morte da Yalorixá Sancha, no ano de 2004, mas cujas atividades, segundo Maria Alice, vão retornar o mais breve possível.

Tonho de Abécio nos levou até o local do terreiro. O barracão se encontra fechado. Maria Alice mora no território. Ela estava roçando e consertando uma cerca quando

\footnotetext{
${ }^{20}$ LESSA, Luciana Falcão. Senhoras do Cajado: um estudo sobre a Irmandade da Nossa Senhora da Boa Morte de São Gonçalo dos Campos - Bahia (1900-1950). Dissertação (Mestrado em História) Universidade Federal da Bahia (UFBA), Salvador, 2005.

${ }^{21}$ Entrevista com Tonho de Abécio.

${ }^{22}$ Entrevista com o senhor Geraldo Alves Pereira. In: LESSA Luciana Falcão. Senhoras do Cajado, p. 175 (anexo n. 1).
} 
chegamos. Fomos apresentados por Abécio. Ela começou a falar do litígio do terreno com um ex-prefeito da cidade de São Gonçalo. E juntamente com o amigo Tonho, passou a contar-me acontecimentos ocorridos no terreiro na época de Tia Sancha:

[...] Aqui Sancha criava porcos, muitos porcos para sustentar a casa. Era uma casa cheia de mulheres. Plantava fumo, feijão, tinha uma cisterna muito boa.Vinham muitas pessoas doidas que traziam pra cá, pessoas endemoniadas, vinham amarradas. Chegavam aqui ela mandava soltar. Teve um dia que chegou uma tal de Rosinha. Chegou doida, amarrada. Mais de dez homens para segurar. Veio do sertão. Chegou com um negócio ruim! Chegou na cisterna e disse: 'ali tem um peixe, vou lá pegar'. Se jogou dentro da cisterna. Tia Sancha chegou. Os pais [da moça] dando chilique, o pessoal apavorado! Tia Sancha chegou e disse: 'Calma, calma, calma! Ela foi para o Ifá. Ogum respondeu que a mulher estava viva, não teve nada. Aí ela mandou vir a corda nova. O homem desceu, pegou ela e acabou. Não teve nada [risos].

Eu era menino, tinha uns dezessete anos, me lembro como se fosse hoje. Assim que ela se jogou, os homens pegaram a corda e tiraram. Ela saiu dando risadas $[\ldots]^{23}$

Foto 3: A cisterna como "suporte" da memória

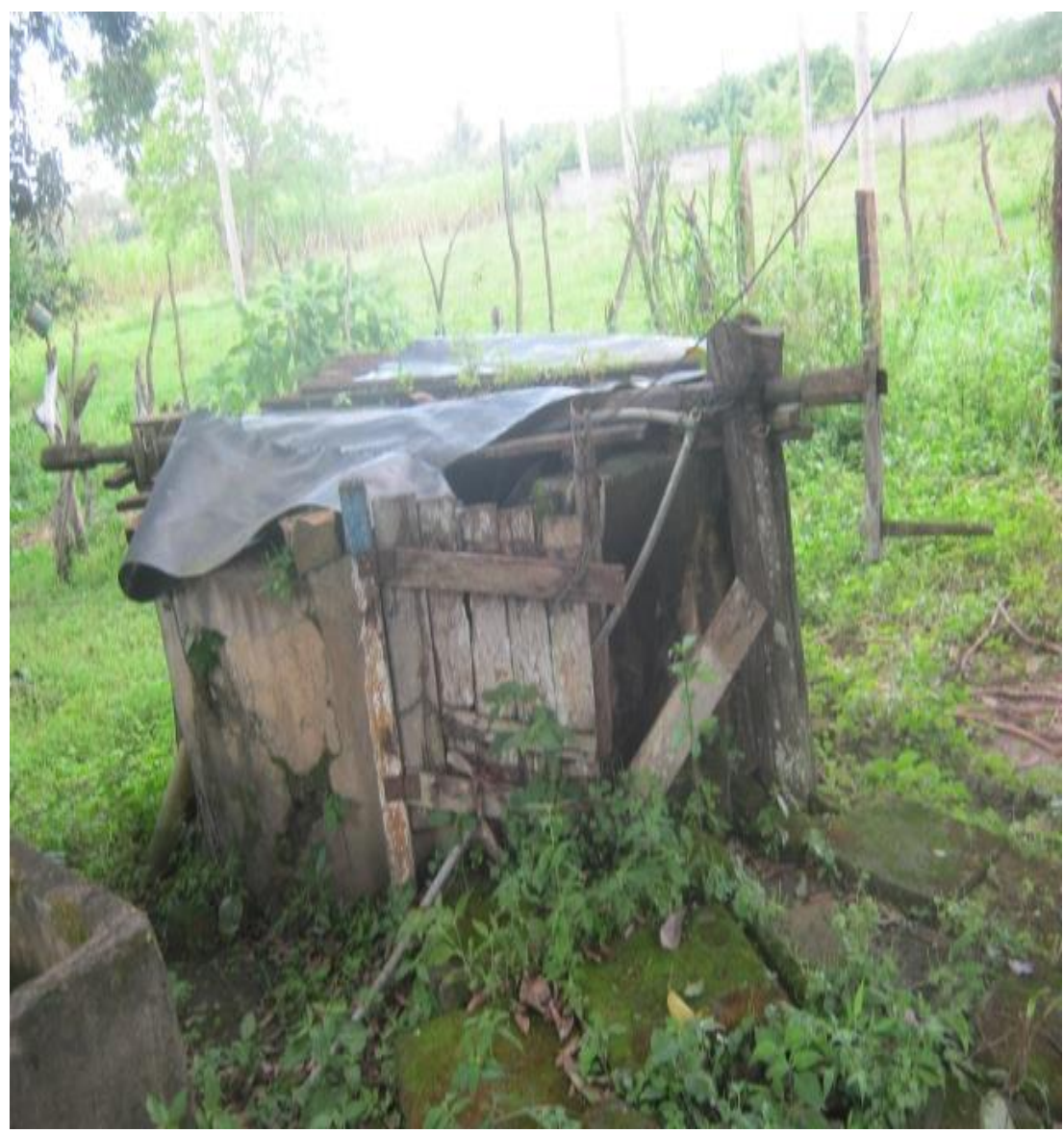

Fonte: Acervo do autor.

\footnotetext{
${ }^{23}$ Entrevistas com Tonho de Abécio e Maria Alice de Araújo.
} 
Além desse depoimento, ouvimos outros acerca da Yalorixá Sancha, inclusive de pessoas que não conviveram com ela, mas que, através da tradição oral, tomaram conhecimento de seu axé. Estivemos no terreiro juntamente com Tonho de Abécio, como mencionamos acima. Para ele, foi um revistar fatos passados. O terreiro é de certa forma, para quem viveu o passado, um lugar de memória, diríamos até, um espaço sagrado da memória individual e coletiva, razão pela qual os filhos feitos por Sancha lutam para a sua manutenção, malgrado os embates do cotidiano, tal qual o relatado por Maria Alice, envolvendo o então prefeito da cidade, que, ao que nos parece, tinha "outros planos" para as terras daquela localidade. Tonho de Abécio corroborou Maria Alice.

O processo de iniciação de Sancha é recorrente na tradição oral de São Gonçalo dos Campos. Tivemos oportunidade de ouvi-la das diversas pessoas com as quais conversamos. Um processo complexo, uma vez que, como nos disseram, a princípio ela não estava disposta a assumir o compromisso com as entidades. E mais: ao que nos parece, ela não tinha muita escolha, uma vez que a entidade "a escolheu" ainda na sua infância, talvez um Orixá de família ${ }^{24}$. Entre as narrativas sobre a iniciação e atuação de Sancha, escolhemos a de Renailda Cazumbá:

[...] Sancha foi proibida de sair de casa desde os oito anos de idade. O santo dela deu este encargo, proibiu ela de sair de casa. Nunca saiu de casa [...]. Pra conhecer Sancha tinha que ir lá!

Ela, um dia, abriu o pote para pegar água, e aí o Orixá se manifestou. A partir daí foi trabalhar ela e tudo. Uma das exigências foi ela não sair de casa. Então ela já assumiu desde pequena.

Era o terreiro de Sancha! Eu mesma nunca vi [Sancha], só via mesmo se fosse lá no terreiro. Ela nunca casou, não teve filhos, tinhas as sobrinhas $[\ldots]^{25}$

Tonho de Abécio corroborou Renailda, frisando que o processo de iniciação de Sancha foi muito conturbado, porque, segundo ele, nem ela, Sancha, nem sua mãe, Hortência, aceitaram de imediato a "escolha" do Orixá. Mas há um dito popular que diz: “ou vai [se inicia] pelo amor, ou pela dor". Parece-nos que o caso dela foi mesmo pela dor, mas, depois de iniciada, desempenhou com êxito sua missão ao longo dos seus 93 anos de idade.

De acordo com o senhor Geraldo Alves Pereira, em depoimento anterior já mencionado, o terreiro de Tia Sancha estabeleceu a relação dos terreiros e yalorixás com a Irmandade da Boa Morte. Segundo ele, vinha gente de muito longe para participar: “Ah! Tinha o da Tia Sancha, vinha gente do sertão todo. ${ }^{26}$

\footnotetext{
${ }^{24}$ Uma herança familiar.

${ }^{25}$ Entrevista com Renailda Cazumbá, em São Gonçalo dos Campos (BA), em 20 de julho de 2015.

${ }^{26}$ Entrevista com Geraldo Alves Pereira. In: LESSA Luciana Falcão. Senhoras do Cajado, p. 176.
} 
As lembranças são como uma linha de novelo, basta puxar uma ponta e ela se põe a desenrolar-se, nem damos conta do tempo, pois parece fugir entre os nossos dedos. Não foi diferente com a narrativa de Renailda: as lembranças de Sancha desenrolaram as suas memórias a partir da infância. Lembrou-se de uma outra yalorixá, vizinha de onde moravam. Esta ela conheceu pessoalmente e fazia questão de presenciar a sua incorporação por um orixá que se denominava Martinho Pescador:

[...]Tinha também a dona Nem. Ela recebia uma entidade. Isto antes dela assumir o santo. Era um homem, ex-escravo. Era Martinho Pescador. Chegava, tomava conta dela por um dia, um dia e meio. Ela então bebia, bebia, bebia o tempo todo e fumava. Quando a entidade chegava, ele mandava um recado para Cazumbá [pai de Renailda]: 'Diga a Cazumbá para mandar o meu charuto e a minha cachaça'. Cazumbá mandava.

A entidade pintava e bordava com a mulher. A entidade previa, lia para as pessoas, passava trabalho. A entidade dizia que era o Martinho Pescador. No outro dia ela estava acabada, porque ele [Martinho Pescador] bebia. Despejava assim [faz gestos de quem bebe na própria garrafa].

Era nossa vizinha. Eu via! A gente ia lá ver o Martinho. Quando ele chegava, ela se transformava. As meninas chamavam a gente para ir ver. Depois ela trabalhou [iniciou-se], abriu um terreiro em outro lugar. ${ }^{27}$

As fotografias abaixo revelam o momento da entrevista, no local do terreiro, quando Tonho e Maria Alice revisitaram o passado. Maria Alice nos presenteou com uma fotografia de Tia Sancha. Para os que a conheceram, como Tonho, essa fotografia é mais que uma recordação, é um lugar de memória ${ }^{28}$. Talvez por isso tenha nos recomendado que a guardássemos com muito carinho.

Após a entrevista, no momento da transcrição, fomos cotejando a narrativa de Tonho com as fotografias que tínhamos em mãos, conferindo os dois documentos que nos revelaram um pouco da face da yalorixá que incorporava Ogum, ou melhor, que se apresentava sobre o rosto dele. Um deus guerreiro, senhor da guerra e do ferro, no corpo de uma mulher que tinha, segundo Abécio, um coração divino.

\footnotetext{
${ }^{27}$ Entrevista com Renailda Cazumbá.

${ }^{28}$ Tomamos emprestado o conceito de Pierre Nora, para caracterizarmos a fotografia como algo que evoca um passado vivido por uma pessoa ou grupo.
} 
Foto 4: Maria Alice (sobrinha de Sancha) e Tonho de Abécio

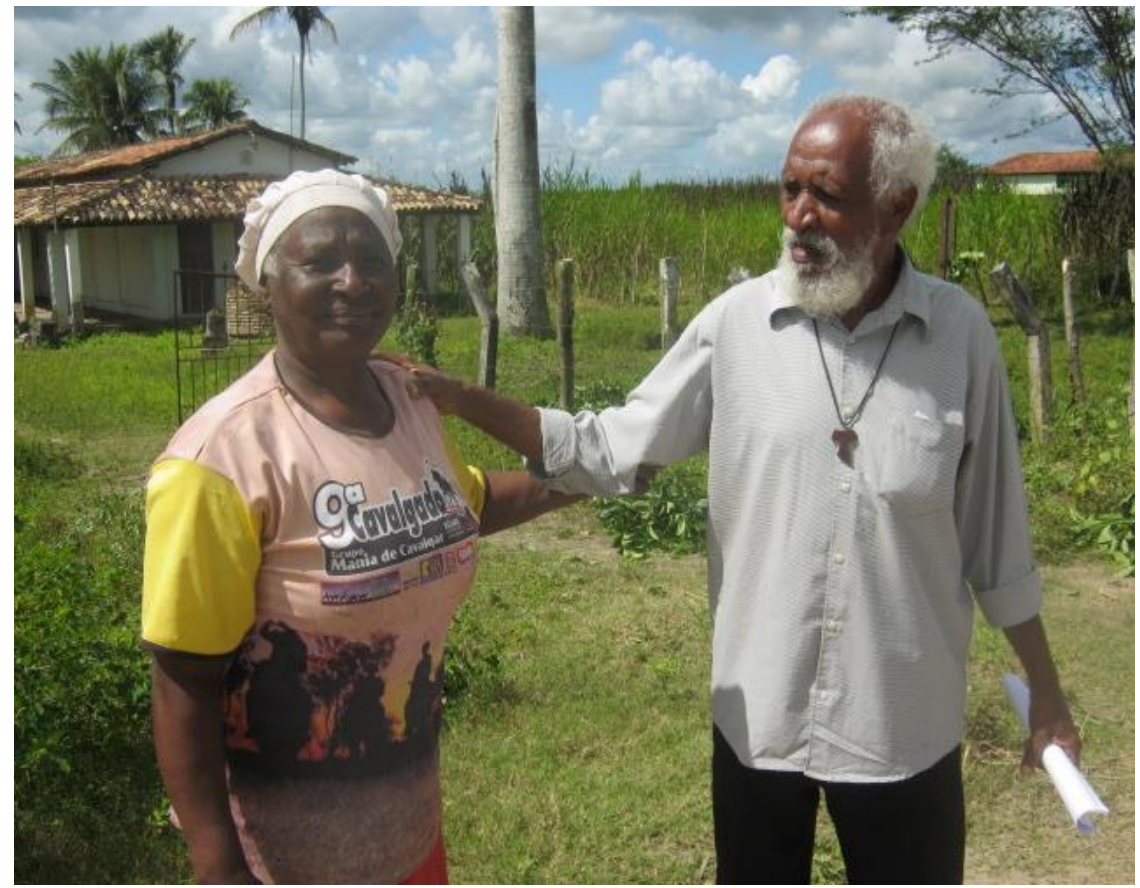

Fonte: Acervo do autor.

Foto 5: O Barracão com os acentos dos Orixás (na varanda, segundo Abécio, acolhiamse os pobres)

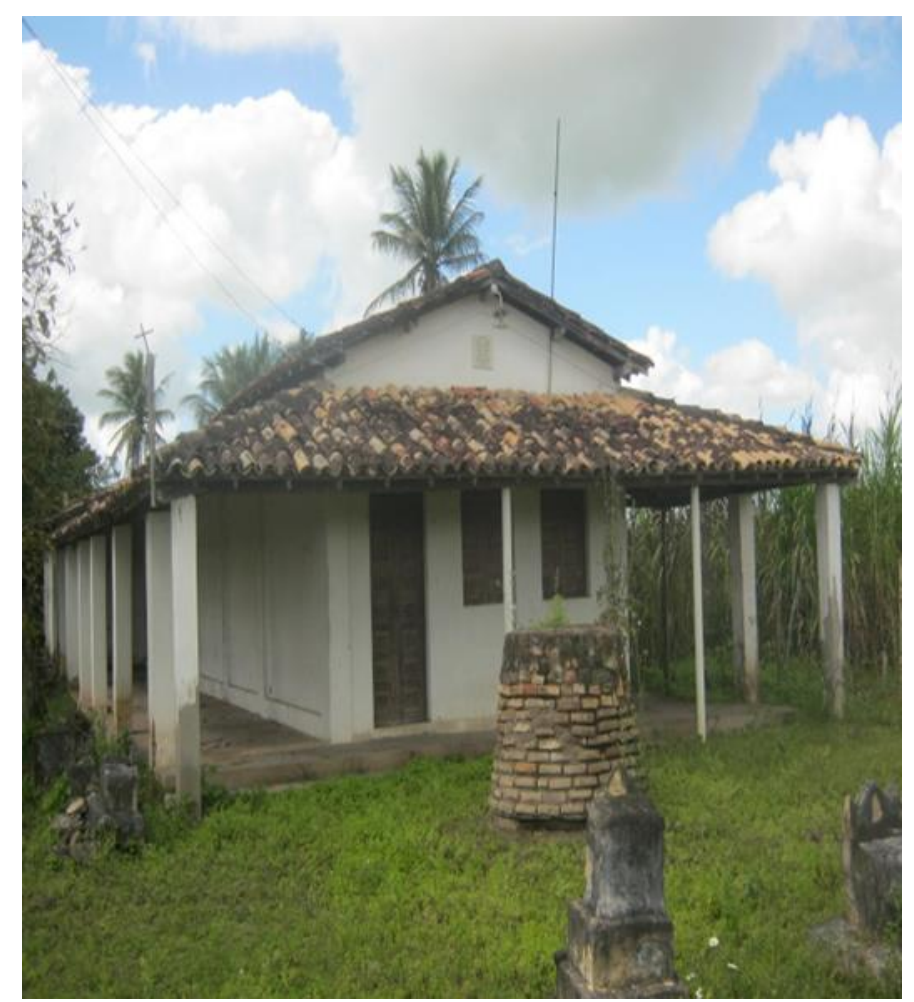

Fonte: Acervo do autor. 
Foto 6: Foto de Maria Sancha Araújo, doada por Maria Alice

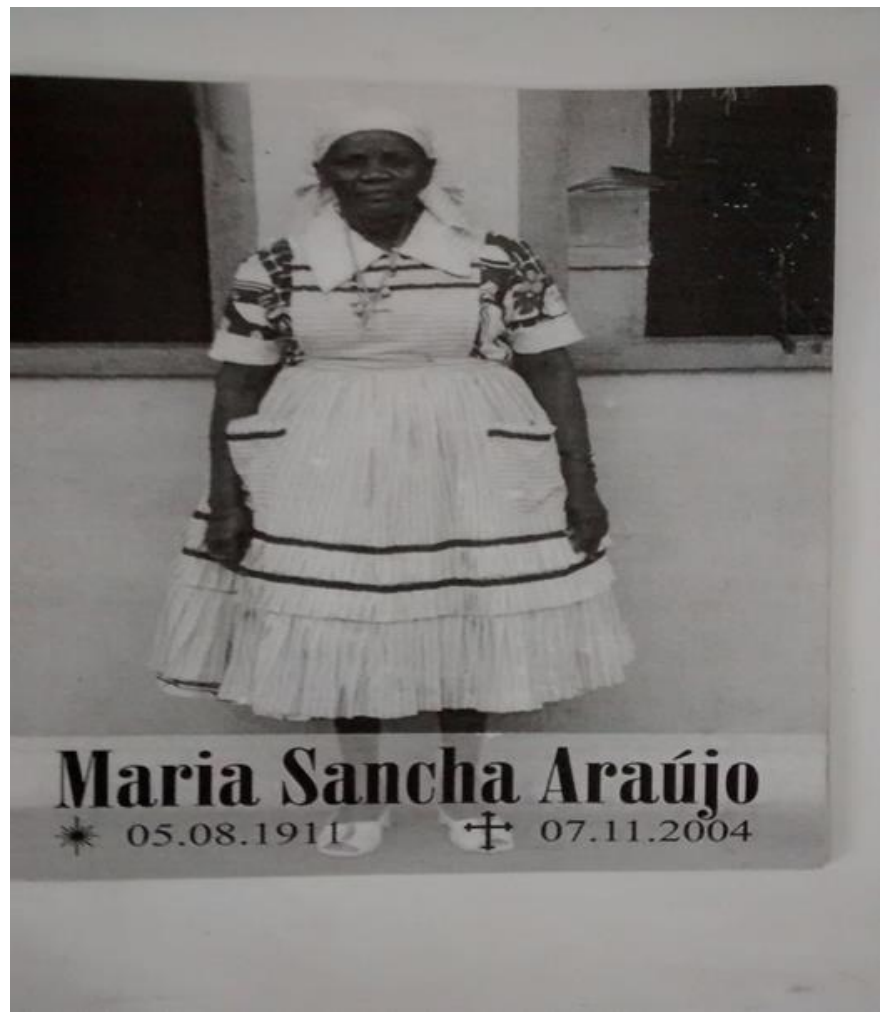

Fonte: Acervo do autor.

A Foto 6 atesta a descrição de Tonho de Abécio: "Era uma preta bonita, uma mulher de um coração divino. Ela usava um avental, lenço na cabeça! Era uma preta alta, bonita! Sancha era filha única de Hortência, o pai era João, morreu cedo"29.

A fotografia avivou a memória de Tonho, tanto quanto de Maria Alice ${ }^{30}$. Eles relembraram, entre risos, mediados de silêncios obsequiosos, alguns fatos passados na casa. Em determinado momento, Abécio lembrou cantando: “[...] Quando Ogum da casa chegava, ele cantava: 'Vamos todos trabalhar pela fé! Vamos todos trabalhar pela fé! Que nosso mestre justo é quem ama a Deus, também ama Jesus, no céu, na terra, nos clareia a luz! Ogum, êh! [...]"

Maria Alice e Abécio, quando perguntados sobre a iniciação de Sancha, contaram que ela sofreu muito, pois nem ela nem sua mãe queriam que ela assumisse a religiosidade. Tonho disse que Sancha sofreu muito antes de aceitar o santo. Maria Alice justificou as razões pelas quais Tia Sancha relutava a iniciar-se:

\footnotetext{
${ }^{29}$ Entrevista com Tonho de Abécio.

${ }^{30}$ Sobre a relação entre fotografia e História, ver: KOSSOY, Boris. Fotografia e História. São Paulo: Ateliê Editorial, 2001.
} 
No início ela não aceitava, nem a mãe dela aceitava. Ela dizia que labutar com gente dentro do candomblé não era vantagem. Era desvantagem, porque ambição, olho grande, inveja [...]. E foi o que aconteceu mesmo! Veja que ela dava cinquenta pratos de comida, de manhã, meio-dia e de noite. A gente tinha que botar a mesa, mas ela não comia. Ela só ia comer lá pelas onze horas da noite, se caso sobrasse. Se não sobrasse nada, ela fazia um mingau de Santo Antônio. ${ }^{31}$

Tonho ouvia atenciosamente a narrativa e completava com alguns detalhes esquecidos por Maria Alice, e concluiu, olhando fixamente para a fotografia: "Esta mulher tinha um Ogum divino, só fazia o bem. Foi uma mulher santa, esta varanda [aponta para o barracão] ela aumentou para acolher os mendigos. Esta casa é uma casa abençoada por Deus! $!^{32}$

\section{A Memória e o Espaço Religioso: À Guisa de Conclusão}

Desde o falecimento de "Tia Sancha" que não se ouvem mais os toques dos atabaques, as vozes dos ancestrais, mas nenhum dos três está mudo: Rum, Rumpi e Lé ${ }^{33}$ voltarão a transmitir as mensagens dos ancestrais, conforme dona Maria Alice. Na opinião de Tonho de Abécio, já está demorado por demais. Foi nesse contexto em que ele relembrou, cantando, quando da chegada de Ogum na casa, nos dias de culto. Ele iniciou a cantiga, no que foi acompanhado por Maria Alice: “[...] Quando o Ogum da casa chegava, ele cantava: 'vamos todos trabalhar pela fé, que nosso mestre justo é! Quem ama a Deus também ama Jesus no céu, na terra. Nos clareia luz! Ogunhê!”.

Nossa conversa se deu, como já foi mencionado, no espaço religioso e, com certeza, influenciou nas formas de lembrar, afinal, ambos vivenciaram rituais nos tempos de 'Tia Sancha'. Segundo Abécio, Maria Alice era ainda criança, ele já com 15 ou 16 anos. Lembraram nomes de pessoas que participavam das festas, entre risos e silêncios. Tal experiência nos remeteu ao constatado por Maurice Halbwachs, ao investigar a relação entre memória coletiva e o espaço religioso:

[...] Quando entra numa igreja, num cemitério, num lugar sagrado, o cristão sabe que vai encontrar lá um estado de espírito do qual já teve experiência, e

\footnotetext{
${ }^{31}$ Entrevista com Maria Alice Araújo

${ }^{32}$ Entrevista com Tonho de Abécio.

33 “'.... São três os atabaques em um terreiro, Rum, Rumpi e Lé, sendo o Rum o atabaque maior com som mais grave - é o atabaque responsável em puxar o toque do ponto que está sendo cantado. No Rum, ficariam os Alabês, Ogãns [sic], ou Ogãns de Sala, como é conhecido por todos; seria o Ogãn responsável pelos toques. O Rumpi seria o segundo atabaque maior, tendo como importância responder ao atabaque Rum, e o Lé seria o terceiro atabaque, onde fica o Ogãn que está iniciando ou aprendiz, que acompanha o Rumpi [...] Cada atabaque tem suas obrigações a serem feitas, pois o atabaque praticamente representa um orixá". (PORTAL 10 NOTÍCIAS. Ogãn e Atabaques. Publicado em $1^{\circ}$ maio 2011. Disponível em: http://filhoscomfe.blogspot.com.br/2011/05/ogan-e-atabaques-rum-rumpi-le.html. Acesso em: 26 abr. 2016).
} 
com outros fiéis, vai reconstruir, ao mesmo tempo, além de uma comunidade visível, um pensamento e lembranças comuns, aquelas mesmas que foram formadas e mantidas em épocas anteriores, neste mesmo lugar [...]. Podemos até mesmo nos afigurar de que a memória de nosso grupo é também contínua como os locais nos quais parece que ela se conserva e que, sem interrupção, uma mesma corrente de pensamento religioso teria passado sob estas abóbodas. ${ }^{34}$

Foi neste contexto que Maria Alice se lembrou das refeições oferecidas às pessoas que frequentavam os cultos, sobretudo os mais carentes. Estávamos em frente ao "barracão" 35, onde, segundo Tonho, ele dançara muito para Ogum. O barracão é, nesse caso, suporte material para as lembranças dos que nele dançaram para os ancestrais em outros tempos. E mais, ao se despedirem, Tonho manifestou o desejo de ver o barracão reabrir, para novamente dançar para os Orixás naquele espaço sagrado.

As narrativas acerca das Yalorixás em São Gonçalo dos Campos remetem ao passado. A pergunta que não quer calar: onde estão as Yalorixás do tempo presente? Pouco me falaram delas, ou melhor, pouco ficamos sabendo das atuais casas de cultos afros na cidade, mas é certo que elas existem, talvez mais "invisíveis" do que antes, devido à preponderância dos templos das igrejas pentecostais, que se colocam como inimigas figadais dos cultos afro-brasileiros, como apontam os noticiários cotidianos em jornais e na mídia em geral. Constatamos diversos templos dessa vertente religiosa na cidade, aliás, um "fenômeno" que vem ocorrendo em todo o território nacional, qual seja, uma verdadeira "proliferação", um templo a cada esquina... ${ }^{36}$ Mas a relação entre os cultos afros e a igrejas pentecostais em São Gonçalo, no passado e no presente, é assunto para outras conversas com Tonho de Abécio, Maria Alice e os que têm na memória as lembranças das zeladoras dos Orixás de um tempo que já passou.

Data de submissão: 15/08/2019

Data de aceite: 02/04/2020

\footnotetext{
${ }^{34}$ HABWACHS, Maurice. A memória coletiva. São Paulo: Centauro, 2004, p.161-162.

35 Ver Foto 6.

36 Sobre esta questão, ver: SILVA, Vagner Gonçalves da (Org.). Intolerância religiosa: impactos do neopentecostalíssimo no campo religioso afro-brasileiro. São Paulo: Edusp, 2007.
} 
Referências

Livros, Dissertações e Teses:

BENJAMIN, Walter. Obras Escolhidas: magia e técnica, arte e política. São Paulo: Brasiliense, 1993.

BOFF, Leonardo. O Rosto Materno De Deus. Petrópolis: Vozes, 2012.

CAPONE, Stefania. A busca da Africa no candomblé. Rio de Janeiro: Pallas, 2004.

FORD, Clyd W. O Herói com rosto africano: mitos da África. São Paulo: Selo Negro, 1999.

HABWACHS, Maurice. A memória coletiva. São Paulo: Centauro, 2004.

KOSSOY, Boris. Fotografia e História. São Paulo: Ateliê Editorial, 2001.

LANDES, Ruth. A Cidade Das Mulheres. Rio de Janeiro: Ed. UFRJ, 2002.

LESSA, Luciana Falcão. Senhoras do Cajado: um estudo sobre a Irmandade da Nossa Senhora da Boa Morte de São Gonçalo dos Campos - Bahia (1900-1950). Dissertação (Mestrado em História) - Universidade Federal da Bahia (UFBA), Salvador, 2005.

NASCIMENTO, Luiz Claúdio Dias do. Terra De Macumbeiro: redes de sociabilidades africanas na formação do candomblé jêje-nagô em Cachoeira e São Félix - Bahia. Dissertação (Mestrado em Antropologia) - UFBA, Salvador, 2007.

NORA, P. Entre Memória e História: A Problemática dos lugares. Projeto História, Revista do Programa de Estudos Pós-Graduados em História e do Departamento de História da PUC-SP, São Paulo, n. 10, 1993.

PARES, Luis Nicolau. A Formação do candomblé: História e ritual da nação jeje na Bahia. Campinas: Ed. Unicamp, 2006.

RAMOS, Arthur. Introdução à antropologia brasileira. Rio de Janeiro: Ed. da Casa do Estudante, 1943. v. 1 (As culturas não européias). (Coleção Estudos Brasileiros da CEB).

SILVA, Vagner Gonçalves da (Org.). Intolerância religiosa: impactos do neopentecostalismo no campo religioso afro-brasileiro. São Paulo: Edusp, 2007.

SPALDING, Tassilo Oepheus. Dicionário das mitologias europeias e orientais. São Paulo: Ed. MEC; Cultrix, 1973.

Sites Eletrônicos:

DOBURU. A Nação Angola: Lenda de Nzaze, Uma lenda sobre Zumba, Ngunzu, Nkisi Nkosi, Ndandalunda, Pambu. s.d. Disponível em: http://daburu.ucoz.com.br/index/a_nacao_angola_lenda_de_nzaze_uma_lenda_sobrezu mba_ngunzu_nkisi_nkosi_ndandalunda_pambu_njila/0-43. Acesso em: 12 ago. 2019. 
PORTAL 10 NOTÍCIAS. Ogãn e Atabaques. Publicação: $1^{\circ}$ maio 2011. Disponível em: http://filhoscomfe.blogspot.com.br/2011/05/ogan-e-atabaques-rum-rumpi-le.html.

Acesso em: 26 abr. 2016.

WIKIPEDIA. Verbete: São Gonçalo dos Campos. https://pt.wikipedia.org/wiki/S\%C3\%A30_Gon\%C3\%A7alo_dos_Campos. Acesso em: 11 abr. 2020

\section{Entrevistas:}

Antônio Raimundo Nunes Costa, "Tonho de Abécio", 71 anos. Em São Gonçalo dos Campos (BA), em 22 de julho de 2015.

Maria Alice de Araújo. Em São Gonçalo dos Campos (BA), em 22 de julho de 2015.

Renailda Cazumbá. Em São Gonçalo dos Campos (BA), em 20 de julho de 2015.

\section{Periódicos:}

Jornal A Razão. 09.01.1948. 